November - 2009

\title{
From Open Content to Open Course Models: Increasing Access and Enabling Global Participation in Higher Education
}

\author{
Tannis Morgan \\ British Columbia Institute of Technology, Canada
}

Stephen Carey

University of British Columbia, Canada

\begin{abstract}
Two of the major challenges to international students' right of access to higher education are geographical/economic isolation and academic literacy in English (Carey, 1999; Hamel, 2007). The authors propose that adopting open course models in traditional universities, through blended or online delivery, can offer benefits to the institutions and to the open education movement itself, in particular with non-Anglophone students. This paper describes the model and an implementation with undergraduate students in Canada, Mexico, and Russia.

The implementation of the model was examined in three studies, which relied on data collected from student interviews, instructor observations and reflections, instructor interviews, course documents, and discussion forum transcripts. The authors note that the main benefit of an open course model is the development of academic literacy for students of English as an Other Language (EOL). Other benefits include 1) international course transfers, 2) breadth of professorial exposure for the students, 3) flexibility in professors' employment and professional development, and 4) course credits for students. Some of the challenges include 1) varying levels of Internet access, 2) coordination of the participation of the instructors, and 3) different teaching and learning practices.

The authors conclude that an open course model might be applied in various contexts, such as in disciplines where global perspectives are important, in applied/professional programs, and in distance or face-to-face courses. Also, the model is useful for students working together on research, case studies, or joint projects, and it could be applied within an institution to enhance inter-disciplinary content and approaches.
\end{abstract}

Keywords: Open access; OER; Open Education Resources; OpenCourseWare; open models; OCW; academic literacy; English as an Other Language 


\section{Open Course Model}

Two of the major challenges that limit international students the right of access to universal higher education are geographical/economic isolation and academic literacy in English (Carey, 1999; Hamel, 2007). The open education resource (OER) movement has largely focused on promoting and enabling the creation and distribution of educational resources and OpenCourseWare (OCW) to a global audience. While there is much to be gained through the open sharing of content being created across global education systems, in particular where access to education presents a challenge, we propose that the next step is to examine how adopting open course models in traditional (bricks and mortar) universities can offer benefits to the institutions and to the open education movement itself. In this article we propose an open course model that can enable global participation in courses (with or without the use of OERs) being offered at educational institutions. The open model for cross-institutional collaboration that we propose is sensitive to concerns of local/global knowledge and reduces the barriers presented by higher education institutions that require that international students become members of their institutions to participate in courses. It also provides an opportunity for international students from developing and developed countries to efficiently develop their EOL (English as an Other Language) academic literacy, now essential to provide access to reading and publishing research in the international academic community (Carey, 1999, 2002; Carey \& Morgan, 2005; Thorne \& Black, 2007).

We propose that both an international and OER/OCW agenda can be facilitated through the adoption of this open course model. This paper describes the model, its implementation in one course with undergraduate students located in universities in Canada, Mexico, and Russia, and its benefits and challenges. The purpose of this paper is to stimulate thinking about how current thinking about OERs and internationalisation can converge in a way that addresses the challenges and the opportunities created by the rapid expansion of Internet capabilities.

\section{Background}

Huijser, Bedford, and Bull (2008) raise the issue that "everyone has the right to education" and "higher education shall be equally accessible to all on the basis of merit," as described in Article 26 of the Universal Declaration of Human Rights. However, access to education is a multipronged problem. To begin, access to higher education on a global scale is denied to a majority of the world's population because they also lack access to the education that permits them to develop the required "merit" for higher education. Secondly, since academic publications are published in English predominantly, global access to tertiary education increasingly requires reading and writing literacy in academic English.

At a local level, access to education has long been a focal point of the distance education agenda in Canada and is a founding ideal of the open university system (Bates, 2005). However, in Canada, at least, there is some evidence that the social agenda of distance education has been eroded with the increase in adoption of information communication technologies (ICTs) and educational technology in dual mode institutions (Bullen, Belfer, \& Burkle, 2008), where ICT 
uptake is viewed as enhancing campus face-to-face (f2f) courses. Concurrently, there is an increased emphasis on an internationalisation agenda at Canadian higher education institutions (AUCC, 2008), resulting in the development of jointly offered programs, partnerships, and study abroad exchanges. However, current models have not addressed how international participation can occur in these institutions and programs without the barriers of entrance requirements, including academic English literacy, tuition fees, and the financial ability to travel and to stay at the host institution, while being sensitive to issues of social and cultural capital, language, and academic literacies.

Clearly, OERs and OCWs have great potential for providing access to knowledge for the global public, including underprivileged and isolated students in developed and developing countries who are excluded from higher educational opportunities. However, to promote efficient learning in most cases these OCWs and OERs must be supplemented with an academic structure that allows students to receive instruction and credit for these courses if they wish to pursue an academic qualification or degree. In this regard, we echo Lane's (2008) concern:

People may be able to access OERs on their own, outside of the constraints of a university, but what recognition and benefits do they gain from doing so if universities still require prior achievement for entry, and employers recognized only those achievements made at universities? (p. 155).

Since the financial means to commute to as well as to pay tuition and to live at internationally renowned foreign institutions of higher learning remains problematic, new models for global access are needed. To more fully address the issue of global access, an unprecedented capacity for inter-institutional cooperation at diverse levels of university governance is needed. However this cooperation has not been forthcoming as many institutions become even more geared to the financial bottom line as a predominant business model.

\section{Current Open Models}

Following MIT's highly acclaimed move to make its educational resources freely available, the number of open learning initiatives has continued to grow (see http://en.wikiversity.org/wiki/Wikiversity:Main_Page). There has been considerable effort on the part of international organizations, such as UNESCO, open universities (e.g., http://openlearn.open.ac.uk/), and public and private institutions, to make educational content and courses freely available through the Internet. At the time of this writing, the OpenCourseWare Consortium (see http://www.ocwconsortium.org/) has brought together more than 200 institutions and organizations providing open educational resources. What began as an effort to provide content has inspired the development of OER course models, ranging from largely selfdirected/access-on-your-own types of learning to open-course-with-open-teaching (including credits for some). In particular, the open teaching efforts of David Wiley (see http://chronicle.com/article/When-Professors-Print-Their/19017), Alec Couros (see http://eci831.wikispaces.com/), and George Siemens and Stephen Downes (see 
http://tc.umanitoba.ca/connectivism/) have stimulated thinking about how students can participate in higher education globally without the usual barriers to access.

We have two concerns with current open teaching models. First, once the novelty of this type of model has worn off it might not be attractive to late adopters because it appears to require a good deal of unpaid effort on the part of the instructor. Secondly, to date, the ability for students to receive credit for their participation is still a work-in-progress. Membership or affiliation with the host institution is required to receive credit, which represents a traditional model.

\section{Language, Culture, and Academic (English) Literacy}

While the challenges to access to education are often identified as economic, geographical, and cultural, language, in particular English, is also a powerful gatekeeper. D'Antoni (2008) has stated

In terms of using OER, the content must be appropriate, and that raises the issues of culture and language if you are considering content from another institution...content needs to be culturally and linguistically translated. And localization means that it has to be accessible to the learner in his or her own setting. In Europe, this is not an issue, but if you are trying to reach people in a developing country, it is. (p.5)

The barrier here is that there must be resources to ensure this happens (Huijser, Beford, \& Bull, 2008, p. 2). In this regard, we are cognizant of the words of geolinguist William Mackey (1992):

The combined impact of this accelerating mobility, globalization of instant information and uniformization of mass media has lessened the contact between neighbours while increasing the impact of dominant cultures whose massive loudspeakers silence the small voices of local speech and minority cultures. In sum, the far erodes the near and eventually drives it out. (p.43)

From another perspective, Imarorato dos Santos (2008) cautions that there is a perception that access to knowledge provided by the Web is free to everybody when in fact it is limited to a certain learner profile:

There is no consideration of the resources and skills that are essential at the very minimum to benefit from OERs, such as the access to a computer connected to the internet and the level of computer literacy that would enable the individual to search for these resources on the web... OERS might have the potential to open up access to content to a number of learner profiles, but contrary to what the institutional discourse tends to portray, not 
necessarily to all of them. (p. 7)

One particular learner profile that we are concerned with is students seeking access to Englishmedium universities or using OERs produced by these. It has been noted that due to the increasing international dominance of English as the language of academic courses, conferences, and publications, the last few decades have seen English academic literacy become increasingly essential to access at all levels of the education system (Hamel, 2007). Academic literacy as a component of academic socialization (Street, 1984; Lea \& Street, 1998) is a complex process that challenges both native and non-native speakers of English (Duff, 2007). However, in the context of OERs, it must be remembered that the majority of the world's English speakers have a mother tongue other than English. Certainly, the linguistic, cultural, and institutional challenges that both institutions and international students face at Western institutions is well documented (Caroll \& Ryan, 2005; Jones \& Brown, 2007). The above research suggests that the accessibility of OERs, in particular where credentialing is needed, is challenged by academic literacy components, especially when participation in English is required.

In our view, neglecting to address the cultural and linguistic development of OERs could result in a situation found in the current practice in scholarly publishing, where, as Flowerdew (2007) has noted, the combined pressures of "globalization and marketization of the academy" (p.14) have created a situation where more and more non-Anglophone scholars need to write in English for international journals, putting them in a disadvantageous position, one where writing in English is perceived as " a sort of ineluctable necessity (related to both international prestige and editorial needs) rather than a matter of free choice" (Guardiano, Favilla, \& Calaresu, 2007). Simply put, OERs in English could be seen as a threat to local languages, similar to the threat posed by the academic publishing world (Hamel, 2007).

Since it is recognized that academic literacy remains a barrier for EOL students and faculty globally (Flowerdew, 2007), our approach has centred on academic literacy in English as an access issue. Therefore, our model attempts to provide not only a way to allow EOL speakers to engage in knowledge sharing but also to develop academic literacy in English.

\section{Reconceptualising Course Delivery}

This article addresses two issues related to OERs: how an open model can take advantage of existing university structures and their attributes (infrastructure, quality control, access to instructors, credential systems) and how it can allow EOL students to participate globally in a more open environment and thereby develop their academic literacy at English-medium institutions. Reconceptualising course delivery, both online and blended modes, can provide an opportunity to enable global participation and to greatly increase access for students from developing countries. If it is agreed that courses are composed of three central components content, interactions, and assessed activities (Figure 1) - then it is possible to consider how technology can facilitate local and international teaching and learning in each of these related components. 


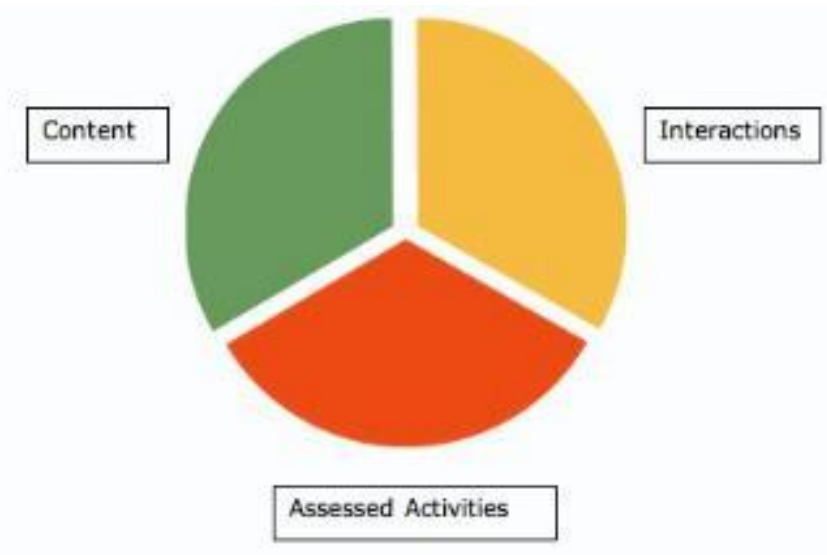

Figure 1. General course components.

The model allows the use of OERs to support the content component of a course. However, the model is founded on the (social-constructivist) assumption that while content is important, the value of a course largely comes from the instructor-student and/or the student-student interaction. Whenever international collaboration and cooperation stand to benefit all parties, technology can be used to facilitate this type of exchange on an efficient, economical, and environmentally friendly scale. In particular, the interaction component can be opened up to a larger (global) audience. For example, there are opportunities to share interaction components, where students would be able to interact in an online forum for the sections of content that are shared, or perhaps meet in an online forum periodically to engage in cross-disciplinary activities, such as discussion, debates, or joint projects. Reconceptualising course delivery in this way has the benefit of exposing students to a broader spectrum of perspectives and expertise through contacts with diverse cultures and settings, engaging them in a larger community of practice, and facilitating the integration of various topics across diverse contexts. The challenge for instructors is to consider how the interaction component can be opened up, while ensuring that individual student needs are being enhanced through a greater access to expertise. 

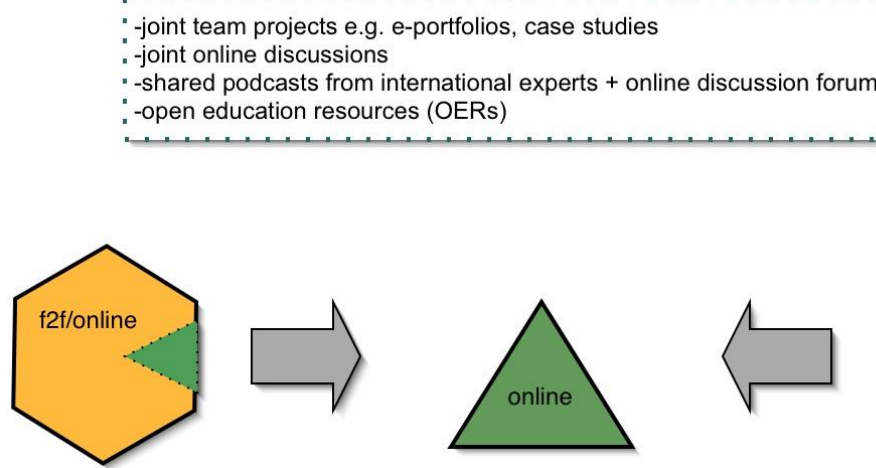

Pediatric dentistry Australia

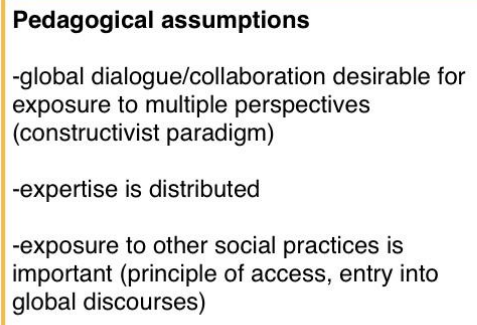

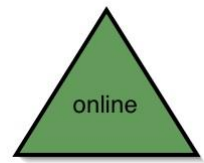
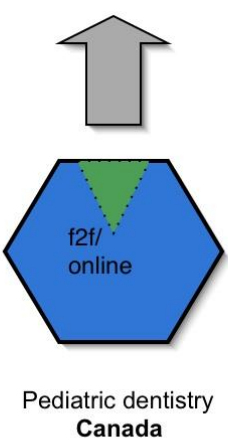

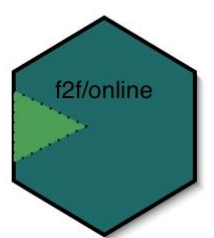

Pediatric dentistry India

Technical/bureaucratic needs

-host institution with support in place

-committed cooperation/investment from all involved course leaders

-similar objectives and scheduling

Figure 2. Open model for inter-university collaboration.

Figure 2 describes our view of how this model could be implemented in a discipline such as pediatric dentistry. Each global site designates a portion of its course to be shared with its partners. In this way, students receive credits from their home institution, but they are able to access a shared component through collaboration with their global partners. For example, $25 \%$ of the course grade would involve the shared component, and the remaining $75 \%$ would come from the regular course components as designated by the home institution. The shared component might include the content, interactions, assessed activities, or any combination of these. The shared component would likely be situated online, but the delivery mode of the local components could be face-to-face or online, resulting in a totally online or a blended mode of delivery for this model.

Although it could be suggested that the model limits participation to students who are enrolled in a university, we emphasize that the model would not only facilitate the use of OERs within a global learning community that students might not normally have access to, but also provide a means of acquiring credits.

\section{Evolution of the Model}

Our own implementation of this model, in effect since its first iteration in 2000, has been motivated by a desire to enable EOL participation within a supportive and fair structure. Because it is recognized that social interaction is a critical component of most online learning (Carey, 1999, 2002; Anderson, 2003; Carey \& Guo, 2003) and much of this research is grounded in the 
social-constructivist principles of Vygotsky (1978; Lee \& Smagorinsky, 2000), particular attention was paid to promoting collaborative critical thinking and writing through the use of an asynchronous discussion forum.

The second author, a professor in Language and Literacy Education, began supplementing his face-to-face campus courses with online discussion boards and quickly noticed that international (EOL) students were much more engaged and contributed to a higher level of discussion in online courses than in regular, face-to-face-only courses. Consistent with other studies (e.g., Lim, 2005), students reported that their academic English improved more from the online than the face-toface components in his mixed-mode classes. In 2000, in order to further enrich the perspectives and engagement in this online discussion, he invited students enrolled in a graduate course at Yakutsk State University in Russia to participate in the online discussions of his graduate course at UBC. This led to the development of a research program that sought to explore intercultural collaboration among students who were enrolled in courses at globally diverse universities and who participated in a common online discussion forum.

In 2001, the model was adapted to enable undergraduate students for whom English was a second language to engage in a global forum. This project involved undergraduate students at three universities, ITESM-Tec de Monterey in Mexico, Yakutsk State University in Russia, and Ritsumeikan University in Japan, who were on a one-year exchange program at the University of British Columbia in Canada. All students were enrolled in credit courses taught in English at their respective universities, and as part of their course requirements they participated in an online discussion forum, involving a total of 123 students from the three universities. The content in the three courses at the participating universities was focused on intercultural understanding and socio-political issues, and the courses were conducted face-to-face and online, in English exclusively. For six weeks students were discussing a variety of issues as part of their course work at their host institution. Each institution allocated and assessed this activity differently and separately, according to its own course syllabus. Students received credit for their participation towards the established requirements of the course that they were enrolled in. In this way, considerable institutional red tape was avoided (Basharina, 2006, Basharina, Guardado, \& Morgan, 2008; Carey \& Morgan, 2005). Figure 3 illustrates the model used in this implementation. 


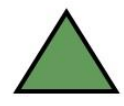

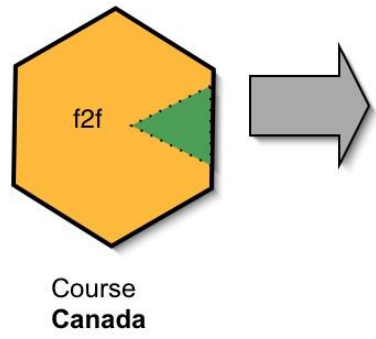
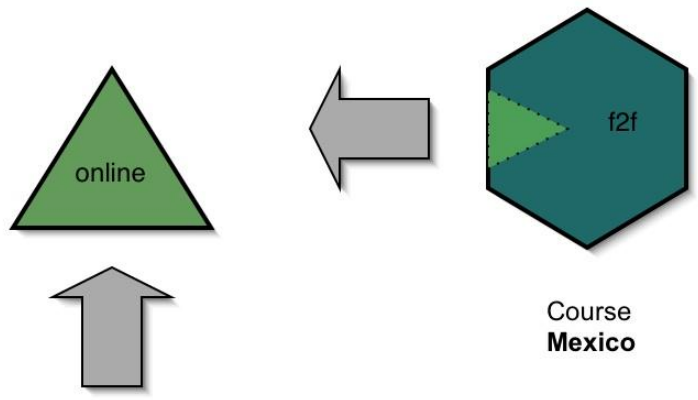

Pedagogical assumptions

-global dialogue/collaboration desirable for exposure to multiple perspectives (constructivist paradigm)

-expertise is distributed

-exposure to other social practices is important (principle of access, entry into global discourses)

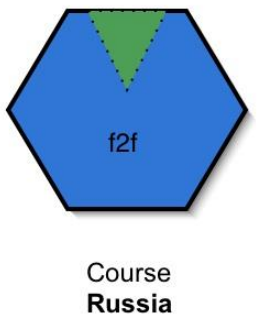

Course

Mexico

Figure 3. Mexico/Canada/Russia implementation of the open model.

This implementation allowed collaboration and participation (via ICTs) with students located in other countries, in other universities, and in other courses. The students received credit at their home institutions yet fully participated in a common online class discussion forum. In some iterations of the model, academic EOL acquisition was a primary goal of the course, while in others academic EOL development was a highly appreciated byproduct of the online academic discussion of course content.

\section{Research Methods}

The implementation of the model involving students from Mexico, Russia, and Japan was examined in three separate studies. These studies explored research questions around intercultural communication and academic literacy development and were guided by sociocultural perspectives and theories as analytical and explanatory frameworks. The three studies relied on data collected from student interviews, instructor observations and reflections, instructor interviews, course documents, and discussion forum transcripts. Basharina (2007) employed ethnographic methods and third generation activity theory (Engestrom, 1987) as an analytical framework. Carey and Morgan (2005) analysed discussion forum transcripts and student interviews to understand the Mexican student experience in the global forum, drawing on second language socialisation and telecollaboration research (Carey, 1999; Kramsch \& Thorne, 2002; 
Furstenberg, Levet, English, \& Maillet, 2001; Weasonforth, Biesenbach-Lucas \& Meloni, 2002). The third study adopted a deliberative-practical action research design (McKernan, 1988) to understand the experiences of the instructors of the Russian, Mexican, and Japanese students (Basharina, Guardado, \& Morgan, 2008).

\section{Benefits and Challenges}

There have been numerous positive results from this model as expressed by undergraduate and graduate students and instructors in questionnaires and interviews (Luo, 2004; Carey \& Morgan, 2005; Basharina, 2007). In particular, the graduate students appreciated the multiple perspectives on course topics from international students in different geopolitical cultures and also in different academic disciplines. EOL professors and students also reported that due to the intense communicative activity on the discussion forum, their ability to write in English in a variety of academic registers improved.

Beyond the development of academic literacy for EOL students, we concluded that the model allows other benefits, which are transferable to other disciplines. To arrive at this conclusion, we have used third generation activity theory (Engestrom, 1987) as an evaluative framework to assess the model. The benefits and challenges outlined below are based on the Mexico/Russia/Canada implementation of the model and are presented as generalized statements about the model.

1. International course transfers: While universities are making progress in establishing course equivalence and credit transfers across universities within countries, admission procedures, transfer credits, and advanced standing on an international level involve complex and time-consuming bureaucratic barriers, and the majority of international students fall through the cracks. This model obviated such complexities by maintaining the specific course requirements and course credits within each course and its home institution, while simultaneously allowing international collaboration of students and professors. Thus, each professor can determine the proportion of their course grade that the shared component represents, and each professor is responsible for grading their students within their particular course. Consequently, the model can allow all participating faculty members and institutions to greatly enhance the academic depth and effectiveness of their courses at no expense.

2. Breadth of professorial exposure for the students: Instead of a single professor, students can have access to two or more professors, who have different cultural perspectives, research backgrounds, and academic expertise.

3. Breadth of international students from different institutions: Having contact with a range of varied backgrounds and training as well as with the educational and professional experience of the students presents an expanded learning opportunity.

4. Flexibility: The flexibility allows professors from different geopolitical co-ordinates to 
be recruited for successive academic terms or years in an academic program. Thus each professor can cover a much wider range of subjects in a given program. Additionally, the professors' own professional development is enhanced through collaboration with their global colleagues.

5. Credits: Most importantly, students can receive credit for their participation in the context of their local courses and programs.

There have been some notable challenges in implementing this model. Although they are described in considerable detail in Basharina, Guardado, and Morgan (2008), we highlight a couple of key points below, specific to the Mexico/Russia/Canada implementation:

1. Varying levels of Internet access among the three partners: While the Mexico and Canada sites enjoyed high-speed Internet access and convenient access to computers, the students at the Russian site had the option of using lab computers in strictly controlled time slots or paying for access at very expensive Internet cafes. As a result, the Russian students took care to compose and read messages offline so as to minimize the online time needed. While the model can be adapted to work with students in particular constraints, clearly it can also fail miserably if such considerations are not included in the design and the implementation. In this regard, the SECTIONS framework (Bates \& Poole, 2002) might be particularly useful to avoid pitfalls caused by insufficient consideration of students and their levels of access in the selection of the technology used in the implementation.

2. Challenges in coordinating the participation of the three instructors: While it was easy to identify willing instructors to take part in the project, the instructors were operating under different constraints in their own teaching contexts. This made it difficult to negotiate items such as project start and end dates, expectations for the shared activity, and degree of instructor involvement.

3. Differing teaching and learning practices: Basharina's (2005, 2007) study illuminated the extent to which teaching and learning practices at a local level can collide in a global arena. For example, different understandings of a course activity and differing norms of participation emerged despite an attempt to establish guidelines and expectations at the outset.

\section{Future Directions}

We have learned through the implementation of multiple variants of the model that there are considerable advantages to an approach that benefits instructors, students, and institutions, but there is also much to be learned from its challenges. We considered how this model might be applied to other disciplines where global perspectives are of particular importance (e.g., business, ecology, medicine). Additionally, we envisioned that applied and professional programs, such as dentistry, medical anthropology, nursing, and environmental studies, might also benefit from this 
model. For example, in a dentistry context, faculty members who have contacts at other institutions and who are teaching similar courses could undertake inter-institutional collaboration projects that enhance a component of their teaching/learning or research. This might involve online discussions about a topic of global interest, case studies that international teams of students work on, or the sharing of content, such as podcasts, among international experts.

Although our own use of this model has centred on international discussions using asynchronous technologies, we suggest that it could be applied to students working together on research, case studies, or joint projects, using a much wider selection of available technologies. In particular, we considered the benefits of applying this model to courses on international aid and disaster relief, world health, global warming, or any topic where rapid international and intercultural cooperation is required, or where local concerns of developing countries need to be addressed. Additonally, the model can be adopted flexibly in both face-to-face and distance learning contexts, or a combination of both, thereby blurring the polarization of these two delivery modes.

We also recognized that while the original intent of the model was to enable students to engage with other students in international contexts, it could be applied within an institution to enhance inter-disciplinary content and approaches. Therefore, the model could facilitate both interuniversity and intra-university exchanges.

\section{Conclusion}

This model does not enable access and participation in global education for the (thankfully) rapidly shrinking groups who might be marginalized by limited Internet access and limited time to devote to academic learning. Nonetheless, we are hopeful that it will encourage institutions to think differently about how their students can engage in a global collaborative conversation that benefits both local and international partners and that breaks down barriers to participation (particularly those faced by EOL students) in academic contexts. This model provides a context in which OERs can be adapted to local situations and contexts and can also provide a more integrated and scholarly venue for academic discussion through the inclusion of diverse scholarly expertise and professional viewpoints. Perhaps in conjunction with the well-established open education and research resources as well as with OER initiatives, it will contribute to a shift towards a culture of openness in the academy (Wiley, 2006). Regardless, it is hoped that this collaborative model and its variants can help to provide access to quality tertiary education to many of the global students, who, to date, have been denied access to education. 


\section{References}

Anderson, T. (2003). Getting the mix right again: An updated and theoretical rationale for interaction. International Review of research on Open and distance Learning, 4(2).

Association of Universities and Colleges of Canada (AUCC) (2008). Internationalizing Canadian campuses. Retrieved from http://www.aucc.ca/_pdf/english/publications/auccscotia_web_e.pdf.

Basharina, O. (2007). Activity theory perspectives on student-reported tensions in international telecollaboration. Language Learning and Technology, 11(2), 82-103.

Basharina, O. (2005). An activity system analysis of international telecollaboration: Contexts, contradictions and learning (Unpublished doctoral dissertation). The University of British Columbia, Canada.

Basharina O., \& Carey, S. (2007). Factors shaping student participation in international computer mediated communication. Polyglossia, 13, 41-52.

Basharina, O., Guardado, M., \& Morgan, T. (2008). Negotiating differences: Instructors' reflections on tensions in international telecollaboration. The Canadian Modern Language Review/La Revue canadienne des langues vivantes, 65(2).

Bates, A. (2005). Technology, e-learning and distance education. New York: Routledge.

Bates, T., \& Poole, G. (2002). Teaching with technology in higher education. San Francisco, CA: Jossey-Bass.

Belz, J.A. (2007) The role of computer mediation in the instruction and development of L2 pragmatic competence. Annual Review of Applied Linguistics, 27, 45-76.

Bullen, M., Belfer, K., \& Burkle, M. (2007, October). Organizational models in dual mode institutions and the social agenda of distance education. Paper presented to the International Council of Distance Educatioin (ICDE) conference, Toluca, Mexico.

Carey, S. (1999). The use of WebCT for a highly interactive virtual graduate seminar. Computer Assisted Language Learning, 12(4), 371-380.

Carey, S. (2002) Principles for mixed mode classes using electronic bulletin boards for second language acquisition. Journal of Applied Linguistics Association of Korea, 17, 29-37.

Carey, S., \& Guo, XG. R. (2003). Conditions for ESL acquisition on WebCT. The International Journal of Learning, 9, 491-498. 
Carey, S., \& Morgan, T. (2005). Intercultural communication in online forums: Exploring new possibilities. Polyglossia, 10, 1-13.

Carroll, J., \& Ryan, J. (2005). Teaching international students: Improving learning for all. London: Routledge.

Duff, P.A. (2007). Problematising academic discourse socialization. In H. Marriott, T. Moore, R. Spence-Brown, \& R. Melbourne (Eds.), Learning discourses and discourses of learning: Vol. 1 (pp. 1-19). Monash University e-Press. Retrieved from http://www.lerc.educ.ubc.ca/fac/duff/personal_website/Publications/Duff Monash 2nd proof corrections.pdf.

D'Antoni, S. (2007). Open educational resources and open content for higher rducation [online roundtable]. Revista de Universidad y Sociedad del Conociemiento (RUSC), 4(1), pp. 17. UOC. Retrieved from http://www.uoc.edu/rusc/4/1/dt/eng/dantoni.pdf.

Engeström, Y. (1987). Learning by expanding: An activity-theoretical approach to developmental research. Helsinki: Orienta-Konsultit.

Flowerdew, J. (2007) The non-Anglophone scholar on the periphery of scholarly publication. AILA Review, 20, 14-27.

Flowerdew, J. \& Yongyan, L. (2007) Plagiarism and second language writing in an electronic age. Annual Review of Applied Linguistics, 27, 161-183.

Furstenberg, G, Levet, S., English, K., \& Maillet, K. (2001). Giving a voice to the silent language of culture: The CULTURA project. Language Learning and Technology, 5(1), 55-102. Retrieved from http://llt.msu.edu/vol5num1/furstenberg/default.pdf.

Guardiano, F., Favilla, E., \& Calaresu, E. (2007). Stereotypes about English as the language of science. AILA Review, 20(1), 28-52.

Hamel, R.E. (2007). The dominance of English in the international scientific periodical literature and the future of language use in science. AILA Review, 20, 53-71.

Huijser, H., Bedford, T., \& Bull, D. (2008). OpenCourseWare, global access and the right to education: Real access or marketing ploy? The International Review of Research in Open and Distance Learning, 9(1). Retrieved from http://www.irrodl.org/index.php/irrodl/article/view/446/1002.

Jones, E., \& Brown, S. (2007). Internationalising higher education. Abingdon: Routledge. 
Kramsch, C., \& Thorne, S. (2002). Foreign language learning as global communicative practice. In D. Block \& D. Cameron (Eds.), Globalization and language teaching (pp. 83-100). London: Routledge.

Lane, A.B. (2008). Widening participation in education through open educational resources. In T. Ilyoshi \& M.S.V. Kumar (Eds), Opening up education: The collective advancement of education through open technology, open content, and open knowledge (pp. 149-163). Cambridge, MA: MIT Press. Retrieved from http://mitpress.mit.edu/books/chapters/0262033712chap10.pdf.

Lea, M., \& Street, B. (1998). Student writing in higher education: An academic literacies approach. Studies in Higher Education, 23(2), 157-173.

Lee, C. D., \& Smagorinsky, P. (Eds.) (2000). Vygotskian perspectives on literacy research: Constructing meaning through collaborative inquiry. New York: Cambridge University Press.

Lim, K. (2005). Second language speakers' participation in computer-mediated discussions in graduate seminars (Unpublished doctoral dissertation). University of British Columbia, Canada.

Luo, Y.L. (2004). A systemic functional perspective on native and non-native English speaking students' online discussion in a mixed-mode graduate seminar (Unpublished doctoral dissertation). University of British Columbia, Canada.

Mackey, W.F. (1992). Mother tongues, other tongues and link languages: What they mean in a changing world. Prospects, 22, 41-52.

Santos, A. (2008). The discourses of OERs: How flat is this world? Journal of Interactive Media in Education. Retrieved from http://jime.open.ac.uk/2008/11/.

Street, B. (1984). Literacy in theory and practice. New York: Cambridge University Press.

Thorne, S.L., \& Black, R.W. (2007). Language and literacy development in computer-mediated contexts and communities. Annual Review of Applied Linguistics, 27, 133-160.

Vygotsky, L. S. (1978). Mind in society. Cambridge, MA: Harvard University Press.

Weasenforth, D., Biesenbach-Lucas, S., \& Christine Meloni (2002). Realizing constructivist objectives through collaborative technologies: Threaded discussions. Language Learning and Technology, 6(3), 58-86.

Wiley, D. (2006). Open source, openness, and higher education. Innovate, 3(1). Retrieved from http://www.innovateonline.info/index.php?view=article \&id=354. 
(a)

SORE RIGHIS RESERNED
Athabasca University 